\title{
Frontiers in Mathematical Analysis and Numerical Methods
}


This page intentionally left blank 
editor

Li Tatsien

Fudan University, China

\section{Ofrantiers in Mathematical Analysis and Numerical Methods}

In Memory of Jacques-Lovis Lions 
Published by

World Scientific Publishing Co. Pte. Ltd.

5 Toh Tuck Link, Singapore 596224

USA office: Suite 202, 1060 Main Street, River Edge, NJ 07661

UK office: 57 Shelton Street, Covent Garden, London WC2H 9HE

\section{British Library Cataloguing-in-Publication Data}

A catalogue record for this book is available from the British Library.

\section{FRONTIERS IN MATHEMATICAL ANALYSIS AND NUMERICAL METHODS In Memory of Jacques-Louis Lions}

Copyright $\odot 2004$ by World Scientific Publishing Co. Pte. Ltd.

All rights reserved. This book, or parts thereof, may not be reproduced in any form or by any means, electronic or mechanical, including photocopying, recording or any information storage and retrieval system now known or to be invented, without written permission from the Publisher.

For photocopying of material in this volume, please pay a copying fee through the Copyright Clearance Center, Inc., 222 Rosewood Drive, Danvers, MA 01923, USA. In this case permission to photocopy is not required from the publisher.

ISBN 981-238-941-5 

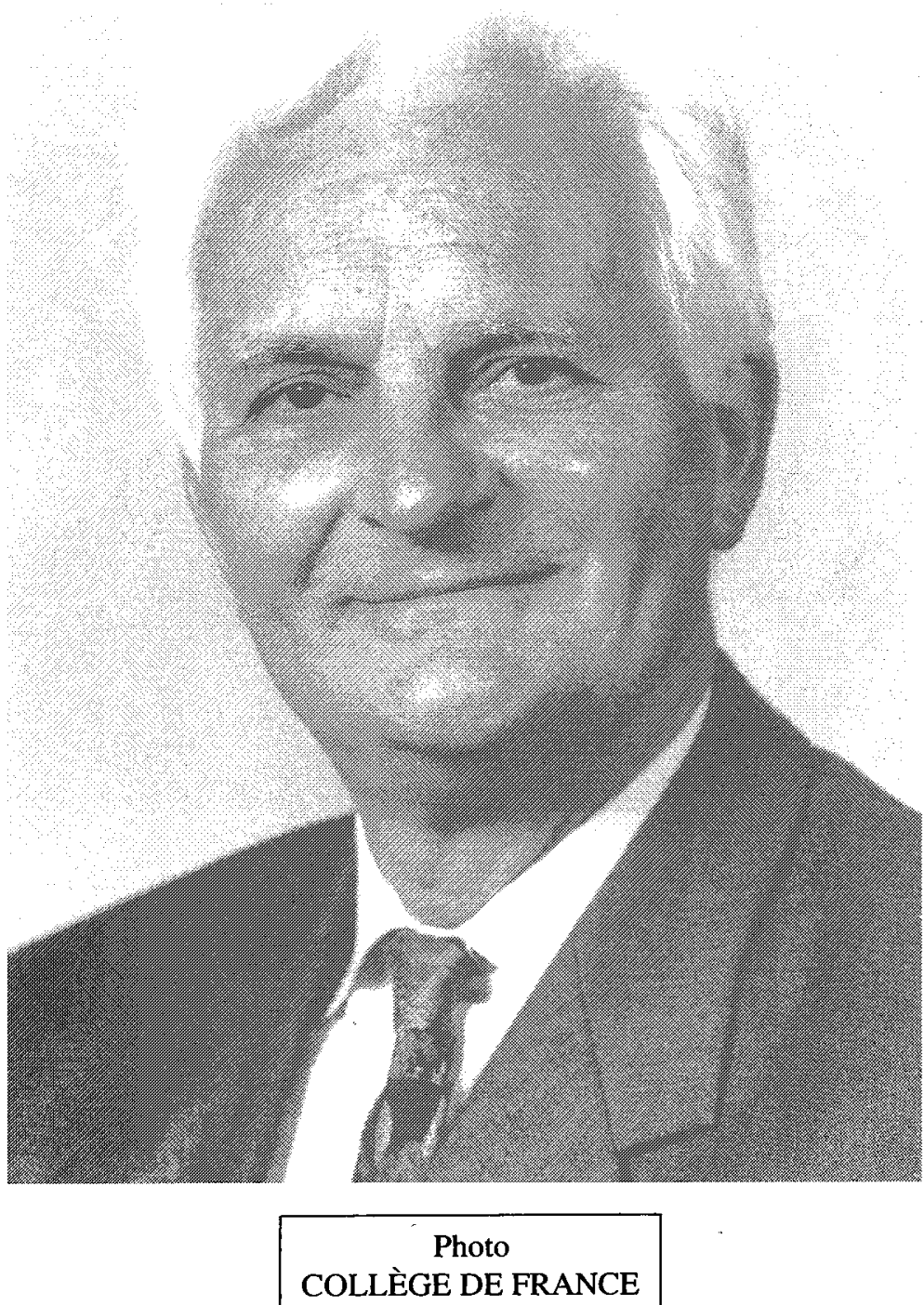

(J.-P. MARTIN)

Mention obligatoire 


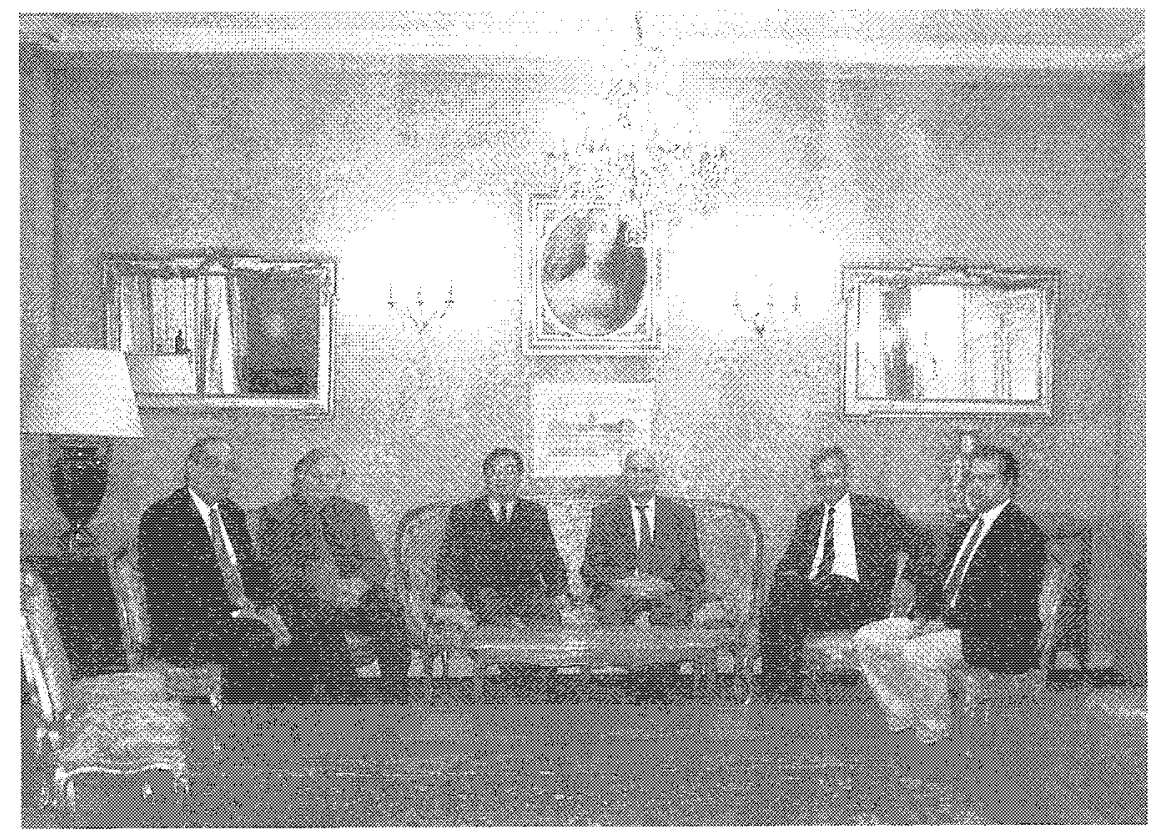

Taken at the Institut de France in Paris on May 29, 2000.

From left to right: A. Damlamian, R. Sénéor, Li Tatsien, J.-L. Lions, P. G. Ciarlet, F. Dubois. 


\title{
PREFACE
}

About three years has passed away since the famous mathematician, a member of the Académie des Sciences de Paris, an oversea Member of the Chinese Academy of Sciences, Professor J.-L. Lions' death. As an outstanding mathematician, he made notable pioneer contributions to many fields of applied mathematics and enjoyed a worldwide high prestige and reputation. He held a series of high-level posts such as President of the IMU (International Mathematical Union), President of the Académie des Sciences de Paris. He played an important role and had a considerable influence in the international community of mathematics. The Journal Chinese Annals of Mathematics published a special issue (Vol. 23, Ser.B, No.2, 2002) dedicated to the memory of Professor J.-L. Lions, carrying papers contributed by his friends, students and colleagues. Afterwards the next several issues of the journal also published some papers of its kind. These papers involve many branches of mathematics and are of high quality and worth preserving. Here we collect them into a volume and offer it to the readers. Meanwhile a short essay of mine in memory of Professor J.-L. Lions is added as a supplement to the article of Professor P. G. Ciarlet, which is a brief account of Professor J.-L. Lions' life and achivements.

I would like to express my thanks to the faculty of the Editorial Office of Chinese Annals of Mathematics, especially to Professor Cai Zhijie and Professor Xue Mi, for their assistance in editing this book.

February 2004

\author{
LI Tatsien (LI Daqian) \\ Department of Mathematics \\ Fudan University \\ Shanghai 200433, China \\ dqli@fudan.edu.cn
}


This page intentionally left blank 


\section{CONTENTS}

Preface vii

Jacques-Louis LIONS, 1928-2001

P. G. CIARLET

Always Remembered

LI Tatsien (LI Daqian)

Stable and Unstable Ideal Plane Flows

C. BARDOS, Y. GUO and W. STRAUSS

Regularity Theory for Systems of Partial Differential Equations with Neumann Boundary Conditions

A. BENSOUSSAN and J. FREHSE

Sensitivity of Darcy's Law to Discontinuities

C. BERNARDI and O. PIRONNEAU

Reiterated Homogenization of Degenerate Nonlinear

Elliptic Equations

J. BYSTRÖM, J. ENGSTRÖM and P. WALL

On the Connection in Finsler Space

S. S. CHERN

Operator-Splitting Methods for the Simulation of Bingham

Visco-Plastic Flow

E. J. DEAN and R. GLOWINSKI 
On the Uniqueness of the Weak Solutions of a Quasilinear Hyperbolic System with a Singular Source Term

J. P. DIAS and M. FIGUEIRA

On the Classification of Initial Data for Nonlinear

Wave Equations

GU Chaohao

Regularity Results for Linear Elliptic Problems Related

to the Primitive Equations

HU Changbing, R. TEMAM and M. ZIANE

Local Exact Boundary Controllability for a Class of Quasilinear Hyperbolic Systems

LI Tatsien and RAO Bopeng

On Nonlinear Differential Galois Theory

B. MALGRANGE

Iterative Algorithms for Data Assimilation Problems

G. MARCHUK and V. SHUTYAEV

Quadrilateral Mesh

MING Pingbing and SHI Zhongci

On the Hyperbolic Obstacle Problem of First Order

J. F. RODRIGUES

Instability of Traveling Waves of the

Kuramoto-Sivashinsky Equation

W. STRAUSS and WANG Guanxiang

Complexity of Large Time Behaviour of Evolution Equations with Bounded Data

J. L. VAZZQUEZ and E. ZUAZUA 